\title{
A Rare Case of Schwannoma of the Superficial Peroneal Nerve with Split Fat Sign
}

Harsh Tantia $^{1 *}$, Deepthi Ashok ${ }^{1}$, Kalaichezhian Mariappan ${ }^{1}$, Venkatraman Indiran ${ }^{1}$, Prabakaran Maduraimuthu ${ }^{1}$ ${ }^{\mathrm{T}}$ Department of Radiodiagnosis, Sree Balaji Medical College and Hospital, Chennai, Tamilnadu, India

\section{Article History}

Received: 18.09.2020

Accepted: 08.10 .2020

Published: 14.11.2020

Journal homepage:

https://www.easpublisher.com/easjms

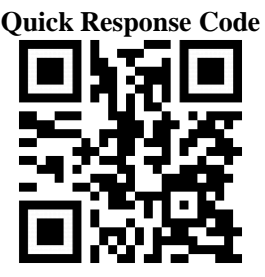

Abstract: Schwannoma of the superficial peroneal nerve is very rare, with only four cases reported till 2006. Unlike neurofibromas, schwannomas do not traverse through the nerve but remain in the sheath lying on top of the nerve. Here we present a rare case of Schwannoma of the superficial peroneal nerve with split fat sign. A 48 year old woman complained of a swelling in the lateral aspect of proximal $1 / 3^{\text {rd }}$ of right leg below the knee joint for 2 weeks. The swelling was painless and very small to begin with but it gradually progressed to the current size of $4 \times 2 \mathrm{~cm}$ and caused mild pain. On examination mild tenderness and increased local warmth was noted at the site of the swelling. Sensations were intact at the site of swelling. There was no history was trauma or co-morbidities. MRI findings revealed a well-defined ovoid lesion which shows isointensity to muscle in T1WI and hyperintensity in T2 STIR, arising from the nerve sheath in the subcutaneous plane lateral to the right fibular neck. Axial and Coronal T2 STIR MR image of right fibular neck shows an image of right fibular neck with a large ovoid lesion which has predominantly high signal and is eccentrically located in distribution of superficial peroneal nerve which has central region low signal intensity representing "target" sign, which is also known as split fat sign. Differential diagnosis considered were schwannoma and neurofibroma. Later bone curettage was performed and histopathology examination revealed findings consistent with schwannoma.

Keywords: Split fat sign, nerve sheath, schwannoma, Neurofibroma, neurofibromatosis type 2 (NF2), Benign tumour, neurilemoma, neurinoma, target sign.

Copyright (C) 2020 The Author(s): This is an open-access article distributed under the terms of the Creative Commons Attribution 4.0 International License (CC BY-NC 4.0) which permits unrestricted use, distribution, and reproduction in any medium for non-commercial use provided the original author and source are credited.

\section{INTRODUCTION}

A 48 year old woman complained of a swelling in the lateral aspect of proximal $1 / 3^{\text {rd }}$ of right leg below the knee joint for 2 weeks. The swelling was painless and very small to begin with but it gradually progressed to the current size of $4 \times 2 \mathrm{~cm}$ and caused mild pain. On examination mild tenderness and increased local warmth was noted at the site of the swelling. The swelling was hard in consistency with restricted mobility. Sensations were intact at the site of the swelling. There was no discharge or abnormal blood vessel at or around the site of the swelling. There was no history was trauma or co-morbidities.

\section{Experimental SECTION}

MRI findings revealed a well-defined ovoid lesion measuring $\sim 4.8 \times 2.6 \times 2.5 \mathrm{~cm}$ which shows isointensity to muscle in T1WI (Figure-1) and hyperintensity in T2 STIR (Figure 2 and 3), arising from the nerve sheath in the subcutaneous plane lateral to the right fibular neck. Axial and Coronal T2 STIR MR image of right fibular neck (Figure 2 and 3 respectively) shows an image of right fibular neck with a large ovoid lesion (green arrow) which has predominantly high signal and is eccentrically located in distribution of superficial peroneal nerve (blue arrow) which has central region low signal intensity representing "target" sign, which is also known as split fat sign. No perilesional oedema or bony destruction was noted. Differential diagnosis considered were schwannoma and neurofibroma. 


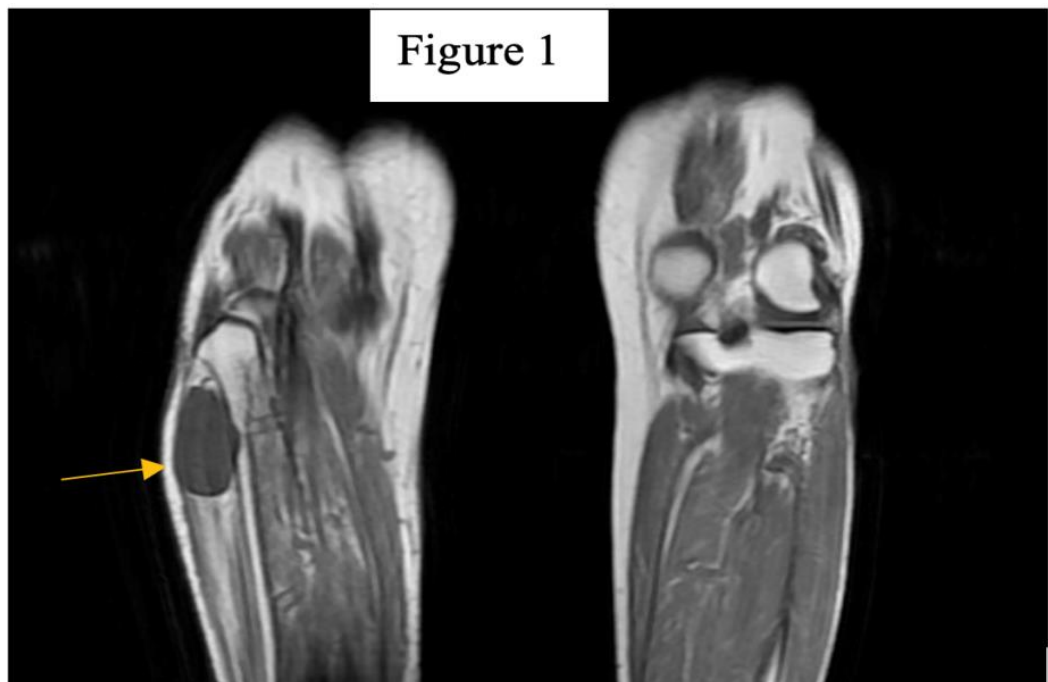

Fig-1: T1WI in coronal plane shows a well-defined ovoid lesion (orange arrow) in the right fibular neck which is isointense to muscle

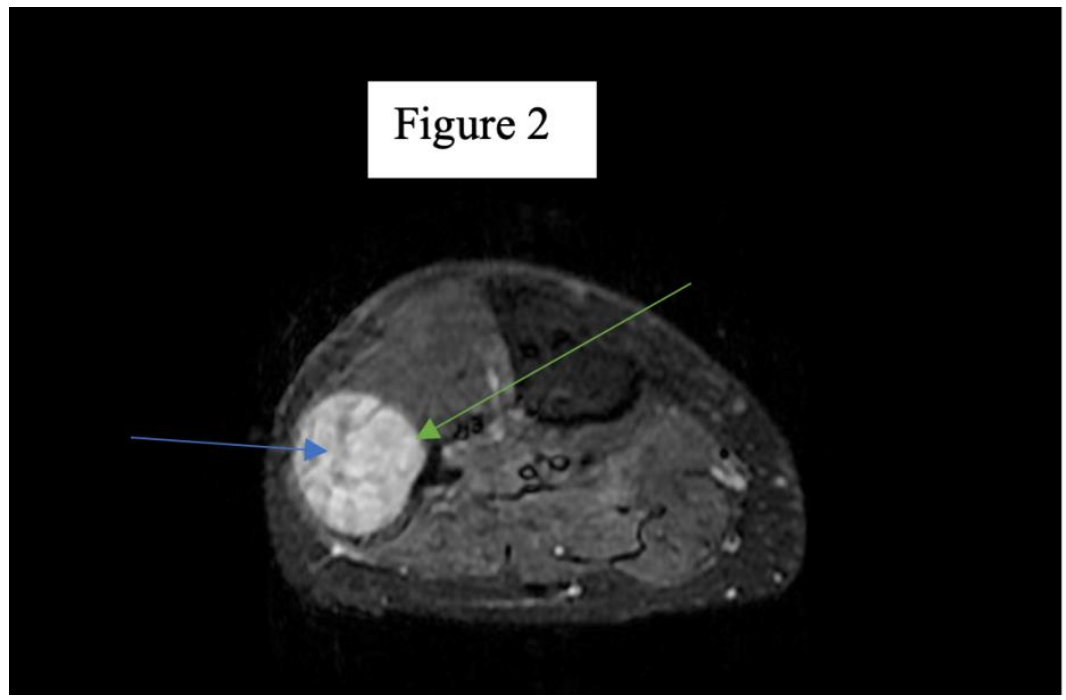

Fig-2: T2 STIR in axial plane shows an image of right fibular neck with a large ovoid lesion (green arrow) which has predominantly high signal and is eccentrically located in distribution of superficial peroneal nerve (blue arrow) which has central region low signal intensity representing "target" sign, which is also known as split fat sign

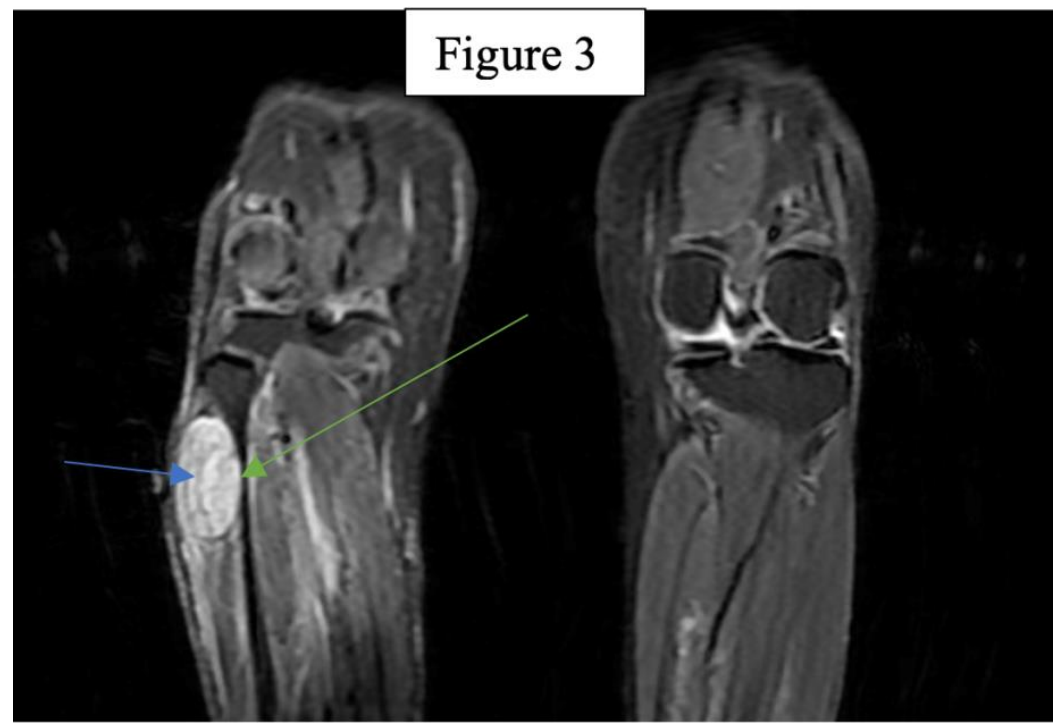

Fig-3: T2 STIR in coronal plane shows an image of right fibular neck with a large ovoid lesion (green arrow) which has predominantly high signal and is eccentrically located in distribution of superficial peroneal nerve (blue arrow) which has central region low signal intensity representing "target" sign, which is also known as split fat sign 


\section{RESULTS AND DISCUSSION}

Later bone curettage was performed and histopathology examination revealed findings consistent with schwannoma.

Schwannomas or neurilemmomas are lobulated, encapsulated tumours that arise from the neurilemmal cells in nerve sheaths [1]. Schwannomas arise from the myelin sheath of nerves and are the most common solitary nerve tumour of the body [2]. Schwannomas can be found in various parts of the body with the most common site being the head. In the lower extremity they are most commonly found in the deep tissues of the foot [3]. Schwannoma of the superficial peroneal nerve is very rare, with only four cases reported till 2006 [4-6]. Unlike neurofibromas, schwannomas do not traverse through the nerve but remain in the sheath lying on top of the nerve. They have a low risk of metastasizing. Schwannomas were found to have some transmission types that were autosomal dominant [7]. It typically is slow-growing, isolated, firm, and round soft tissue mass [8].

Schwannomas can present with no symptoms, mild symptoms or severe symptoms mostly affecting the nerves. Most lesions are solitary and present as a slowly growing painless soft-tissue mass. Symptoms are unusual, unless the mass has become large enough to compress the adjacent nerve [9]. In contrast to neurofibromas and primary malignant nerve sheath tumours, schwannomas are eccentrically placed in relation to the axis of a large peripheral nerve, well encapsulated and can be dissected from the fascicles of the parent nerve without jeopardizing permanent or severe nerve dysfunction $[10,11]$. MRI reveal lowsignal-intensity lesions on T1-weighted sequences, high signal intensity lesions on T2-weighted sequences. Signal on T2-weighted images can be either homogeneously hyperintense or show a characteristic target sign, consisting of a central hypointense region [12].

Conventional schwannomas are composed of two organized cell patterns: Antoni A and Antoni B. These patterns are present in all the cases of conventional schwannoma in varying proportions. The Antoni A pattern is more organized with a palisaded appearance and an elongated, spindle-shaped cellular nucleus. A characteristic appearance in the Antoni A pattern is the Verocay body, which is a circular coalescence of elongated nuclei. The Antoni B pattern is characterized by a diffuse cellular structure with rounded nuclei [13].

\section{CONCLUSION}

Here we present a rare case of Schwannoma of the superficial peroneal nerve with split fat sign.

\section{REFERENCES}

1. Russell RCG, Williams NS and Bulstrode CJK. Bailey and Love's Short Practice of Surgery. 23rd Ed, London: Arnold; 2000.

2. Stout AP. Tumors of the peripheral nervous system. In: Atlas of tumor pathology. Section 2, Fasicle 6. Washington, D.C., Armed Forces Institute of Pathology, 1949.

3. Takada E, Ozaki T, Kunisada T, Harada Y, Inoue H. Giant schwannoma of the back. Arch Orthop Trauma Surg. 2000;120:467-469.

4. Houshian S, Freund KG. Gigantic benign schwannoma in the lateral peroneal nerve. Am J Knee Surg, 1999;12:41-42.

5. Laurencin CT, Bain M, Yue JJ, Glick H. Schwannoma of the superficial peroneal nerve presenting as web space pain. J Foot Ankle Surg. 1995;34:532-533.

6. Thomas GP, Baco AM, Rosenfeld P. Schwannoma of the superficial peroneal nerve. Internet J Orthop Surg. 2006; 3(2):12.

7. Liebau C, Baltzer AW, Schneppenheim M, Braunstein S, Koch H, Merk H. Isolated peripheral neurilemoma attached to the tendon of the flexor digitorum longus muscle. Arch Orthop Trauma Surg. 2003; 123:98-101.

8. Yuk Kwan Tang C, Fung B, Fok M, Zhu J. Schwannoma in the upper limbs. BioMed Research International. 2013;2013:1-4.

9. Schultz E, Sapan MR, McHeffey-Atkinson B, Naidich JB, Arlen M. Case report 872. "Ancient" schwannoma (degenerated neurilemmoma). Skeletal Radiol. 1994; 23:593-595.

10. Knight DM, Birch R, Pringle J. Benign solitary schwannomas: a review of 234 cases. The Journal of Bone and Joint Surgery. British volume. 2007 Mar;89(3):382-7.

11. Kang HJ, Shin SJ, Kang ES. Schwannomas of the upper extremity. Journal of Hand Surgery. 2000 Dec;25(6):604-7.

12. Varma DG, Moulopoulos A, Sara AS, Leeds N, Kumar R, Kim EE, Wallace S. MR imaging of extracranial nerve sheath tumors. Journal of computer assisted tomography. 1992;16(3):44853.

13. Çakmak G, Ulusal AE, Bilgiç S, Tuncay C. Sciatic schwannoma - Rare cause of sciatica: A case report. J Clin Anal Med. 2015; 6:525-7. 